\section{SAT0501 EARLY START OF BIOLOGICAL TREATMENT IN JUVENILE IDIOPHATIC ARTHRITIS: DOES A THERAPEUTIC WINDOW EXIST IN REAL LIFE?}

A. García Fernández ${ }^{1}$, A. Briones-Figueroa ${ }^{1}$, L. Calvo Sanz ${ }^{1}$, Á. AndreuSuárez ${ }^{1}$, J. Bachiller-Corral ${ }^{1}$, A. Boteanu ${ }^{1} .{ }^{1}$ Hospital Ramón y Cajal, Rheumatology, Madrid, Spain

Background: Biological therapy (BT) has changed the treatment and perspectives of JIA patients but little is known about when is the best moment to start BT and the impact of this prompt iniciation.

Objectives: To analyze the response to BT of Juvenile Idiophatic Arthritis (JIA) patients according to the time when the BT was started.

Methods: A retrospective, descriptive study was conducted on JIA patients followed up in a referal hospital that started BT up to 24 months after diagnosis from 2000 to 2018. Disease activity was measured, at 2 years after diagnosis, according to Wallace criteria for remission (absence of: active arthritis, active uveitis, fever, rash or any other manifestation attributable to JIA, normal CRP and ESR, PGA indicating no active disease) for at least 6 months.

Results: $55 \mathrm{JIA}$ patients that started BT up to 24 months from diagnosis were analyzed. $69,1 \%$ were girls with a median age at diagnosis of 8 years old IQR(313), median age at the start of BT of 9 years old IQR(3-13). Regarding JIA categories: $25,5 \%$ were Oligoarticular Persistent (OligP), 18,2\% Systemic JIA (sJIA), 16,4\% Entesitis related Arthritis (ERA), 12,7\% Psoriatic Arthritis (APso) and Polyarticular RF- (PolyRF-), 5,5\% Oligoarticular Extended (OligE) and Polyarticular RF+ (PolyRF+), 3,6\% Undifferentiated (Und). $20 \%$ of patients had uveitis during followup. Conventional DMARD (CDMARD) was indicated in $83,6 \%$ of patients $(95,7 \%$ Methotrexate) at diagnosis [median 0 months IQR(0-2,3)]. At the end of followup (2 years) only $30,9 \%$ of patients continued with cDMARDs. The main causes of discontinuation were: adverse events $(46,7 \%)$, remission $(36,7 \%)$. TNF inhibitors were precribed in $81,8 \%$ of patients and $18,2 \%$ of patients recieved two BT during the first 2 years from diagnosis. $54,5 \%$ of BT were indicated during the first 6 months from diagnosis, $27,3 \%$ from 7 to 12 months, $12,7 \%$ from 13 to 18 months, $5,5 \%$ from 19 to 24 months. After 2 years from diagnosis, $78,2 \%$ of patients were on remission and $21,8 \%$ active. Among patients with active disease: $75 \%$ had arthritis, $16,7 \%$ had uveitis and $8,3 \%$ had both. There were no differences regarding disease activity among patients with uveitis and neither taking cDMARDs. Regarding JIA categories: $66,7 \%$ of OligE, $57,1 \%$ of PolyRF- and $57,1 \%$ of APso patients were active at 2 years from diagnosis when compared to the other categories $(p=0.004)$.

Patients on remission at 24 months from diagnosis started sooner the BT than active patients $[C I$ 95\% $(0,46-8,29) p=0,029]$. The time when the BT was started was correlated to the activity at 2 years $(K=0,294 p=0,029)$. When the $B T$ was prescribed after 7,5 months from diagnosis it was correlated, in a COR curve, with a higher probability of active disease at 2 years $(S=0,67 \mathrm{E}=0,63)$. There was a correlation, among patients on remission at 2 years, between prompt start of $B T$ and less time to reach remission $(K=-0,345 p=0,024)$. Patients with active disease at 2 years, regardless of moment of BT iniciation, required more BT during follow-up $(p=0,002)$.

Conclusion: Prompt iniciation of BT was correlated with a better outcome. JIA patients that started BT early after diagnosis had a higher probability of remission after 2 years. Starting BT after 7,5 months was correlated with a higher probability of active disease at 2 years. Active disease at 24 months was correlated with persistent active disease during follow-up.

Disclosure of Interests: None declared

DOI: 10.1136/annrheumdis-2020-eular.4611

\section{SAT0502 LONG-TERM OBSERVATIONAL SAFETY SURVEILLANCE OF GOLIMUMAB TREATMENT FOR POLYARTICULAR JUVENILE IDIOPATHIC ARTHIRTIS- AN INTERIM ANALYSIS}

G. Horneff ${ }^{1}$, A. Zimmer ${ }^{1}$, K. Minden ${ }^{1}$, T. Hospach ${ }^{1}$, F. Weller-Heinemann ${ }^{1}$, S. Hansmann ${ }^{1}$, J. Kuemmerle-Deschner ${ }^{1}$, M. Fasshauer ${ }^{1}$, N. Hofmann ${ }^{1}$, H. Koessel' ${ }^{1}$, I. Foeldvari', S. Mrusek ${ }^{1}$, D. Windschall ${ }^{1}$, N. Onken ${ }^{1}$, M. Hufnagel ${ }^{1}$, D. Foell', N. Brueck', P. Oommen ${ }^{1}$, F. Dressler', A. Helling-Bakki ${ }^{1}$, A. Klein ${ }^{1}$. ${ }^{1}$ BIKER Registry, Sankt Augustin, Germany

Background: Golimumab (GOL) is approved for treatment of polyarticular juvenile idiopathic arthritis ( $\mathrm{pJIA}$ ) in patients 2 years and older. Data on long-term safety in this indication are limited.

Objectives: Prospective monitoring of long-term safety and effectiveness of $\mathrm{GOL}$ in routine care using the German BIKER registry.

Methods: In this non-interventional study baseline and safety parameters were compared between patients initiating GOL and contemporary matched control cohorts starting either an alternative TNF inhibitor (TNFi) or methotrexate (MTX) without exposure to a biologic. Efficacy outcomes were JADAS10, JIA ACR scores, joint counts and Childhood Health Assessment Questionnaire disability-index (CHAQ-DI). Safety assessments were based on adverse event (AE) reports.
Results: From 2016 to 2019, 55 patients initiating GOL have been recruited and matched to 110 patients starting alternative TNFi and 47 biologic-naïve patients. Patients starting GOL had a longer disease duration $(6.8 \mathrm{y}$ vs. $4.1 \mathrm{y}$ and $1.0 \mathrm{y}$; $p<0.0001)$ and use of GOL was significantly more often second-line ( $85 \%$ vs $31 \%$ and $0 \%, p<0.0001$ ). Disease activity was lower at baseline compared to MTX patients as indicated by active joint counts, JADAS 10 and concomitant steroid use. Otherwise they were comparable with patients treated with other TNFi (Table 1).

Table 1 Comparison of GOL cohort with (1) other TNFi cohort and (2) MTX cohort.

\begin{tabular}{|c|c|c|c|c|}
\hline & $\begin{array}{l}\mathrm{GOL} \\
\mathrm{N}=55\end{array}$ & $\begin{array}{l}\text { Other TNFi } \\
\quad \mathrm{N}=110\end{array}$ & $\begin{array}{l}\text { MTX } \\
\mathrm{N}=47\end{array}$ & $\begin{array}{c}\text { p-value \# } \\
\text { GOL vs } \\
\text { TNFi/MTX }\end{array}$ \\
\hline Gender female, n (\%) & $44(80)$ & $86(78)$ & $34(72)$ & $0.8 / 0.5$ \\
\hline $\begin{array}{l}\text { Age at baseline, mean (SD), } \\
\text { years }\end{array}$ & $13.6(2.8)$ & $13.6(3.0)$ & $13.1(3.4)$ & $1.0 / 0.4$ \\
\hline $\begin{array}{l}\text { Disease duration, mean (SD), } \\
\text { years }\end{array}$ & $6.8(4.5)$ & $4.1(3.8)$ & $1.0(1.6)$ & $<0.0001$ \\
\hline RF neg. polyarthritis, n (\%) & $28(51)$ & $53(48)$ & $29(62)$ & $0.7 / 0.3$ \\
\hline RF pos. polyarthritis, n (\%) & $6(11)$ & $18(16.4)$ & $11(23.4)$ & $0.5 / 0.1$ \\
\hline Extended oligoarthritis, n (\%) & $20(36.4)$ & 37 (33.6) & $6(12.8)$ & $0.7 / 0.007$ \\
\hline Psoriatic arthritis & $1(1.8)$ & $2(1.8)$ & $1(2.1)$ & $1.0 / 1.0$ \\
\hline Pretreatment bDMARD n(\%) & $47(85.5)$ & 34 (30.9) & 0 & $<0.0001$ \\
\hline Concomitant steroids, $\mathrm{n}(\%)$ & $9(16.4)$ & $26(23.6)$ & $25(53.2)$ & $0.3 / 0.0001$ \\
\hline Active joint count, mean (SD) & $4.6(4.0)$ & $5.4(6.1)$ & $9.7(6.5)$ & $0.4 /<0.0001$ \\
\hline CHAQ DI, mean (SD) & $0.4(0.4)$ & $0.5(0.6)$ & $0.6(0.7)$ & $0.3 / 0.07$ \\
\hline ESR, mm/h, mean (SD) & $20.4(27.6)$ & $15.4(18.6)$ & $21.4(18.6)$ & $0.2 / 0.8$ \\
\hline JADAS10, mean (SD) & $11.3(6.0)$ & $12.4(5.8)$ & $16.9(5.4)$ & $0.3 /<0.0001$ \\
\hline AE, n (rate/100PY; 95\%Cl) & $45(96 ; 72-128)$ & $\begin{array}{l}106(114 \\
94-138)\end{array}$ & $\begin{array}{l}39(107 \\
78-146)\end{array}$ & $0.3 / 0.6$ \\
\hline SAE, n (rate/100PY; 95\%Cl) & $2(4.2 ; 1.1-17)$ & $5(5.4 ; 2-13)$ & $1(2.7 ; 0.4-19)$ & $0.8 / 0.7$ \\
\hline $\begin{array}{l}\text { Infectious AE, n (rate/100PY; } \\
\quad 95 \% \mathrm{Cl} \text { ) }\end{array}$ & $6(12.8 ; 5.7-28)$ & $11(11.8 ; 6.5-21)$ & $9(24.5 ; 13-47)$ & $0.9 / 0.2$ \\
\hline $\begin{array}{l}\text { Serious infections, } \mathrm{n} \\
\quad \text { (rate/100PY; } 95 \% \mathrm{Cl})\end{array}$ & 0 & $2(2.2 ; 0.5-8.6)$ & 0 & n.a. \\
\hline Uveitis new manifestation & $1(2.1 ; 0.3-15)$ & $2(2.2 ; 0.5-8.6)$ & 0 & 1.0/n.a. \\
\hline
\end{tabular}

In GOL treated patients a marked clinical response was noted at 6 months and beyond demonstrated by a significant decrease of the mean JADAS 10 from 11.3 to $6.4(\mathrm{p}=0.0008)$, as well as JIA ACR 30/50/70/90 response rates of $56 / 56 / 35 / 21 \%$. JADAS remission and minimal disease activity was observed in $18 \%$ and $47 \%$ after 6 months and in $29 \%$ and $43 \%$ of patients after 12 months.

Rates of AE, SAE and infectious AE were comparable between the GOL cohort (96, 4.2 and 12.8/100PY), the alternative TNFi cohort (114, 5.4 and 11.8/100PY) and the MTX cohort (107, 2.7 and 24.5/100PY). SAE reported in the GOL cohort were uveitis and JIA flare (each 1). Two serious infections, both influenza, were reported in the alternative TNFi cohort, none in the GOL cohort. No case of pregnancy, malignancy or death was reported.

Conclusion: Interim results from this ongoing safety surveillance study indicate acceptable safety and tolerability of GOL in pJIA that is comparable to treatment with alternative TNFi or MTX. The long-term effectiveness data reinforce the established efficacy of GOL in pJIA treatment.

Disclosure of Interests: Gerd Horneff Grant/research support from: AbbVie, Chugai, Merck Sharp \& Dohme, Novartis, Pfizer, Roche, Speakers bureau: AbbVie, Bayer, Chugai, Merck Sharp \& Dohme, Novartis, Pfizer, Roche, Angela Zimmer: None declared, Kirsten Minden Consultant of: GlaxoSmithKline, Sanofi, Speakers bureau: Roche, Toni Hospach: None declared, Frank Weller-Heinemann: None declared, Sandra Hansmann Consultant of: Advisory board Novartis Pharma, Jasmin Kuemmerle-Deschner Grant/research support from: Novartis, Sobi, Consultant of: Novartis, Sobi, Speakers bureau: Novartis, Sobi, Maria Fasshauer Consultant of: Shire, CSL Behring, Nadja Hofmann: None declared, Hans Koessel: None declared, Ivan Foeldvari Consultant of: Novartis, Sonja Mrusek: None declared, Daniel Windschall Speakers bureau: Abbvie, Nils Onken: None declared, Markus Hufnagel: None declared, Dirk Foell Grant/research support from: Novartis, Sobi, Pfizer, Speakers bureau: Novartis, Sobi, Normi Brueck: None declared, Prasad Oommen Consultant of: Novartis, Frank Dressler: None declared, Astrid Helling-Bakki: None declared, Ariane Klein Consultant of: Celgene DOI: 10.1136/annrheumdis-2020-eular.3589

\section{SAT0503 SERIOUS INFECTION RISK IN PEDIATRIC PATIENTS WITH LOW IMMUNOGLOBULIN LEVELS FOLLOWING RITUXIMAB TREATMENT FOR GRANULOMATOSIS WITH POLYANGIITIS (GPA) OR MICROSCOPIC POLYANGIITIS (MPA)}

S. Melega ${ }^{1}$, P. Brogan ${ }^{2}$, G. Cleary ${ }^{3}$, A. Hersh ${ }^{4}$, O. Kasapcopur ${ }^{5}$, S. Rangaraj ${ }^{6}$, R. Yeung ${ }^{7}$, A. Zeft ${ }^{8}$, J. Cooper ${ }^{9}$, P. Pordeli ${ }^{10}$, P. Kirchner ${ }^{11}$, P. Lehane ${ }^{12} .{ }^{1} F$. 